\title{
Shear modulus and damping ratios of transparent soil manufactured by fused quartz
}

\author{
Gang Qiang Kong ${ }^{\mathrm{a}, *}$, Li Duo Zhou ${ }^{\mathrm{a}}$, Zhong Tao Wang ${ }^{\mathrm{b}}$, Gang Yang ${ }^{\mathrm{b}}$, Hui Li ${ }^{\mathrm{a}}$ \\ ${ }^{a}$ College of Civil and Transportation Engineering, Hohai University, Nanjing, China. \\ ${ }^{\mathrm{b}}$ School of Civil Engineering, Dalian University of Technology, Dalian, China. \\ *Correspondence to: Xikang Road No. 1, Nanjing 210098, China. Tel.: +86 258378 \\ 6834. E-mail address: gqkong1 @ 163.com (G. Q. Kong).
}

\section{ABSTRACT}

The mixture of fused quartz and pore fluid with the same refractive index has been used as a synthetic transparent soil to mimic the behavior of natural soil. Previous research has focused on its static properties. In this paper, the dynamic properties of fused quartz (dry samples and oil saturated samples), including shear modulus and damping ratio, were examined through a series of resonant column tests and dynamic torsional shear tests. It was found that fused quartz has similar dynamic behavior to that of natural soil. With the test results, fused quartz shows a great potential as a substitute for natural soil and is expected to be widely used in dynamic transparent soil model tests.

Key words: Porous materials, Elastic properties, Fused quartz, Shear modulus

\section{Introduction}

Visualization model tests on internal flow, temperature and deformation problems in geotechnical engineering could be non-intrusively measured through using synthetic transparent media and Particle Image Velocimetry techniques [1-3]. The mixture of 
transparent granular materials and pore fluid with the same refractive index has been used as a synthetic transparent soil to mimic the behavior of natural soil.

Two main innovative transparent granular materials have been widely used in previous studies. Iskander et al. conducted extensive investigations on granular silica gel for modeling natural soil and its basic static properties, shear modulus and damping ratio have been obtained through triaxial tests and resonant column tests [4-6]. However, silica gel particles are hydroscopic and thus affected by high humidity and water, which can cause the particles to break and become colored; its particles also deform plastically even under low confining pressure. Ezzein \& Bathurst conducted extensive investigations on fused quartz for modeling natural soil [7]. The static properties of fused quartz have been carried out detaily [8]. However, the dynamic properties of fused quartz and the transparent soil manufactured by fused quartz and pore fluid have not been studied. For the further application of fused quartz in order to substitute sand and track particle movement inside soil during dynamic events such as liquefaction that can result from earthquakes, the aim of this work is to study the dynamic properties of fused quartz and transparent soil (which is manufactured by fused quartz and pore fluid with the same refractive index) through a series of resonant column tests and dynamic torsional shear tests. The results of a series of resonant column tests and dynamic torsional shear tests performed on fused quartz are presented to examine its dynamic properties, including shear modulus and damping ratio.

\section{Experiments}


The torsional resonant column test apparatus from Nanjing Technology University, China, was used for the tests according to ASTM D 4015. The torsional force was applied by a torsional drive at first-mode resonance, at frequencies ranging from 20.0 $\mathrm{Hz}$ to $150.0 \mathrm{~Hz}$. The non-contacting sensor was located on extended arms to amplify the rotational deformation providing a shear strain resolution ranging from $10^{-6}$ to $10^{-4}$. The soil samples were $39.1 \mathrm{~mm}$ in diameter and $80.0 \mathrm{~mm}$ in height. The dynamic torsional shear test apparatus from Dalian University of Technology, China, was used for the tests according to ASTM D 7552-09. The non-contacting sensor provided a shear strain resolution ranging from $10^{-3}$ to $10^{-1}$, and the torsional force at frequencies ranged from $0.01 \mathrm{~Hz}$ to $10.0 \mathrm{~Hz}$. The soil samples were $30 \mathrm{~mm}$ at the inner diameter, $70 \mathrm{~mm}$ at the outside diameter and $100 \mathrm{~mm}$ in height.

The transparent soil was manufactured by fused quartz and pore fluid with the same refractive index $(\mathrm{RI}=1.4585)$. Fused quartz was manufactured by firstly melting natural quartz crystals present in quartzite sand at approximately $2000^{\circ} \mathrm{C}$, and then cooling them. The fused quartz used in this study is angular in shape and was manufactured by Jiangsu Kaida Silica Co. LTD in China. Detailed properties can be seen in Ezzein \& Bathurst [7], and Guzman et al. [8]. The particle size used in this paper ranged from $0.5 \mathrm{~mm}$ and $1.0 \mathrm{~mm}$, and the relative density is about $60 \%$. Pore fluid was blended $(75: 25$ by weight $)$ with $\operatorname{Norpar}^{\circledR} 12(\mathrm{RI}=1.4235)$ and Drakeol $^{\circledR} 15$ white mineral oil $(\mathrm{RI}=1.4688)$, the most widely used in model test application till now [9].The transparent soil samples used in this paper were manufactured as follows: 
Firstly, the latex membrane was tied on one end of the platform through the soil sample preparation mold, the bottom of latex membrane was kept sealed. Secondly, pore fluid was poured into the mold until reached $1 / 3$ of the maximum height. Thirdly, measured the weight of fused quartz material, then rained them into the pore fluid slowly. Finally, the top latex membrane was tied on the other end of the platform, the mold was removed and the transparent soil sample was manufactured. An Abbe refractometer (AR200 Digital Handheld Refractometer manufactured by Reichert Analytical Instruments, Depew, NY) was used to measure the refractive index of the mixture's solution.

\section{Results and discussion}

Fig. 1(a) shows the shear modulus, $G$, as a function of shear strain amplitude determined from resonant column tests and dynamic torsional shear tests with a confining pressure of $100 \mathrm{kPa}$ for dry and oil saturation samples. The graphs indicate that the dry specimen has a higher shear modulus than that of the oil saturation specimen. The maximum shear modulus, $G_{\max }$, at a strain level of $10^{-6}$ under $100 \mathrm{kPa}$ confining pressure is about $60 \mathrm{MPa}$ for both the dry and oil saturation specimen.
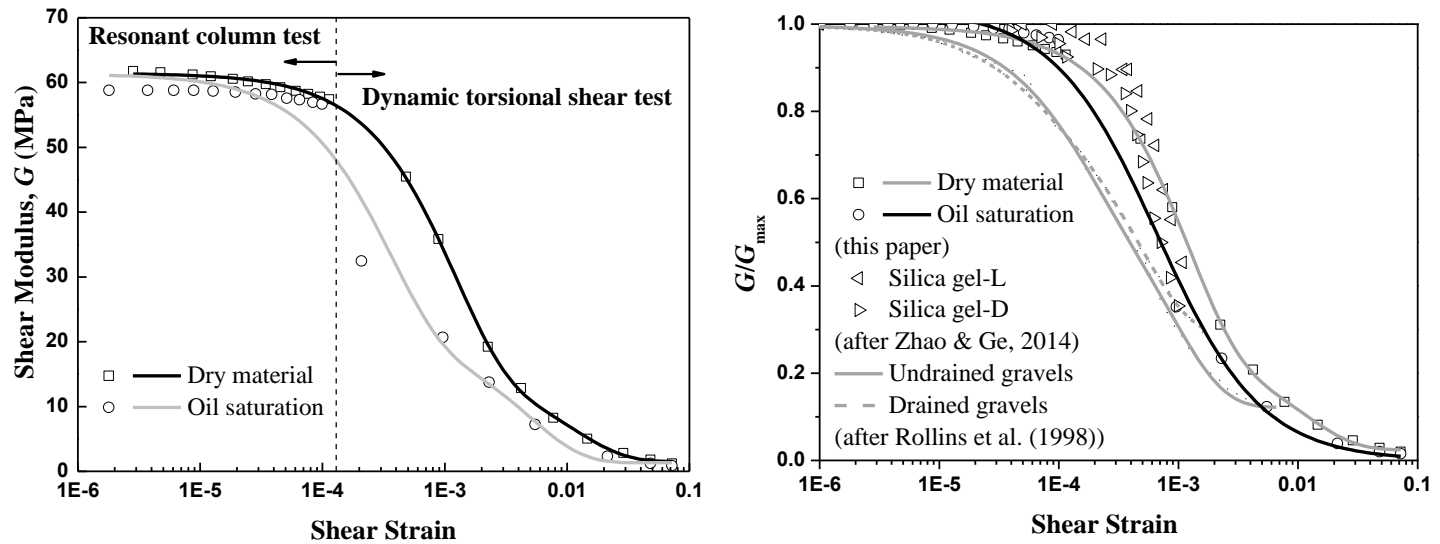
FIG. 1. Shear modulus versus shear strain: (a) dry and oil saturation condition; and (b) normalized comparison.

The normalized shear modulus versus shear strain of tested fused quartz and transparent soil is shown in Fig. 1(b). In order to produce a comparative analysis, the normalized shear modulus versus shear strain of silica gels, $0.5-1.0 \mathrm{~mm}$ in particle size and with a $100 \mathrm{kPa}$ confining pressure (Zhao \& Ge [6]), and gravels under undrained and drained conditions (Rollins et al. [10]) are also shown in Fig. 1(b). The results indicate that the normalized shear modulus for fused quartz has a similar distribution with silica gel materials and gravels.

The damping ratios, $\zeta$, were determined by the amplitude decay method according to ASTM D 4015. The damping ratio as a function of shear strain amplitude determined from resonant column tests with a confining pressure of $100 \mathrm{kPa}$ is given in Fig. 2 for dry and oil saturation samples. The damping ratio versus shear strain for silica gel (Zhao \& Ge [6]) and gravels (Rollins et al. [10]) is also shown in Fig. 2 for comparative analysis. The damping ratio firstly displayed a slow linear increase, and then showed a rapid nonlinear increasing behavior with the increasing of the shear strain; the dry specimen of fused quartz has a lower damping ratio than that of the oil saturation specimen. The results from Fig. 2 also showed that the damping ratios of both fused quartz and silica gel were similar to those of the natural soil reported by Rollins et al. [10].

Unified formulas for the damping ratio of sand after summarized the previous 
researcher's data were proposed by Ishibashi \& Zhang [11], and Zhang et al. [12]. The formulas expressed the damping ratio for sand or saturated soils (from South Carolina,

North Carolina, and Alabama) as a function of $G / G_{\max }$ as follows:

$$
\begin{gathered}
\zeta=0.333\left[0.586\left(\frac{G}{G_{\max }}\right)^{2}-1.547\left(\frac{G}{G_{\max }}\right)+1\right] \quad(\text { after Ishibashi and Zhang) } \\
\zeta-\zeta_{\min }=10.6\left(G / G_{\max }\right)^{2}-31.6\left(G / G_{\max }\right)+21.0 \quad \text { (after Zhang et al.) }
\end{gathered}
$$

The damping ratios (both fused quartz of dry and oil saturation specimens, and silica gel) versus $G / G_{\max }$ are shown in Fig. 3, on which the fitting curve of Eqs. (1) and (2) are plotted. Although a short of range of $G / G_{\max }$ data has been obtained in this paper, existing laboratory test data for transparent soil are distributed closer to the fitting curve (based on the data of sand) by Ishibashi \& Zhang [11].

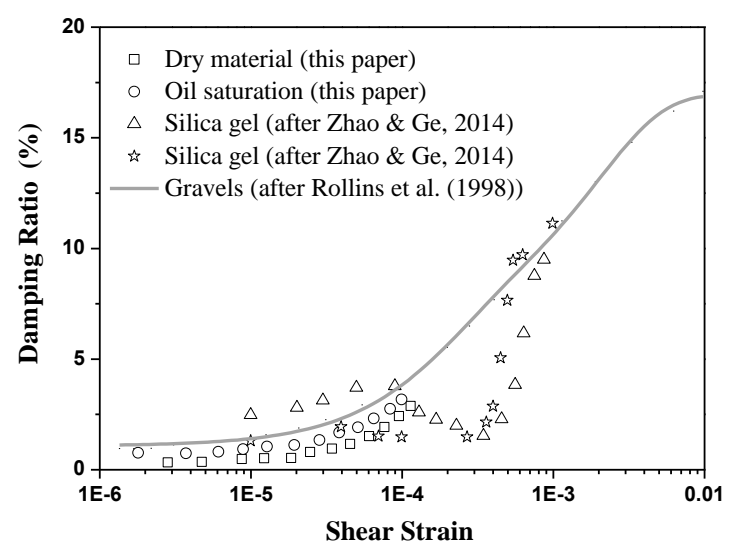

FIG. 2. Comparison of damping ratios.

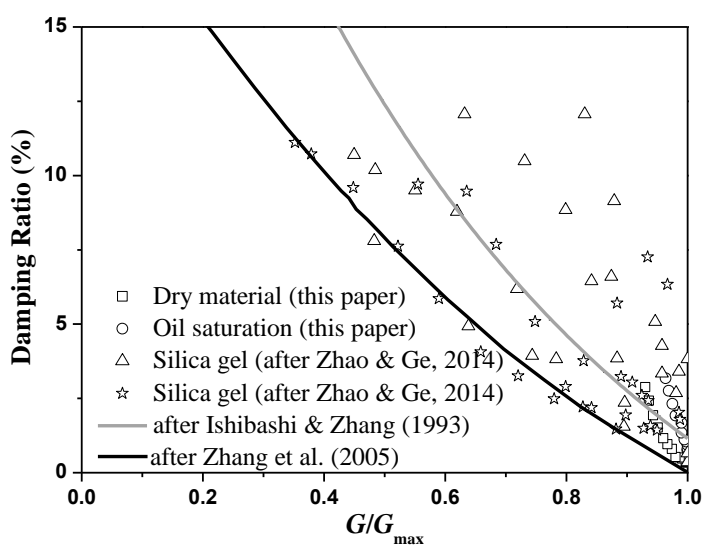

FIG. 3. Damping ratios versus normalized shear modulus.

\section{Conclusions}

In this paper, the shear modulus and damping ratio of fused quartz with dry and oil saturation are comprehensively studied. The dry specimen has a higher shear modulus 
than that of the oil saturation specimen. The maximum shear modulus, $G_{\max }$, at a strain level of $10^{-6}$ under a $100 \mathrm{kPa}$ confining pressure is about $60 \mathrm{MPa}$ for both dry and oil saturation specimens. The relationships between the normalized shear modulus (or damping ratio) and shear strain of fused quartz are found to follow the same general trend as those of natural soil. Testing findings show that fused quartz could at a certain degree simulate the behavior of the natural soil, though some differences exist between them.

\section{Acknowledgements}

The research was financially supported by the National Science Foundation of China (51478165), and the fundamental research funds for the central universities of China (No. 2013B31814, 2014B07214). We are also grateful Dr. ZZ Meng at École Polytechnique Fédérale de Lausanne for her help.

\section{References}

[1] Serrano RF, Iskander M, Tabe K. 3D contaminant flow imaging in transparent granular porous media. Geotech Lett 2011; 1: 71-8.

[2] Hird CC, Ni Q, Guymer I. Physical modeling of deformations around piling augers in clay. Geotechnique 2011; 61: 993-9.

[3] Ezzein FM, Bathurst RJ. A new approach to evaluate soil-geosynthetic interaction using a novel pullout test apparatus and transparent granular soil. Geotext Geomembranes 2014; 42: 246-55.

[4] Iskander M, Liu J, Sadek S. Transparent silica gels to model the geotechnical 
properties of sand. Int J Phys Modell Geotech 2002; 2: 27-40.

[5] Liu JY, Iskander M, Sadek S. Consolidation and permeability of transparent amorphous silica. Geotech Test J 2003; 26: 1-12.

[6] Zhao HH, Ge L. Investigation on the shear moduli and damping ratios of silica gel. Granul Matt 2014; 16: 449-56.

[7] Ezzein FM, Bathurst RJ. A transparent sand for geotechnical laboratory modeling. Geotech Test J 2011; 34: 1-12.

[8] Guzman IL, Iskander M, Suescun-Florez E, Omidvar M. A transparent aqueous-saturated sand surrogate for use in physical modeling. Acta Geotechnica 2014; 9: 187-206.

[9] Iskander M, Bathurst RJ, Omidvar M. Past, present, and future of transparent soils. Geotech Test J 2015; 38: 557-573.

[10] Rollins KM, Evans MD, Diehl NB, Daily WD. Shear modulus and damping relationships for gravel. J Geotech Geoenviron Eng 1998; 124: 396-405.

[11] Ishihara K, Zhang XJ. Unified dynamic shear moduli and damping ratios of sand and clay. Soils Found 1993; 33: 182-91.

[12] Zhang JF, Andrus RD, Juang CH. Normalized shear modulus and material damping ratio relationships. J Geotech Geoenviron Eng 2005; 131: 453-464.

\section{Figure Captions}

FIG. 1. Shear modulus versus shear strain: (a) dry and oil saturation condition; and (b) normalized comparison. 
FIG. 2. Comparison of damping ratios.

FIG. 3. Damping ratios versus normalized shear modulus. 


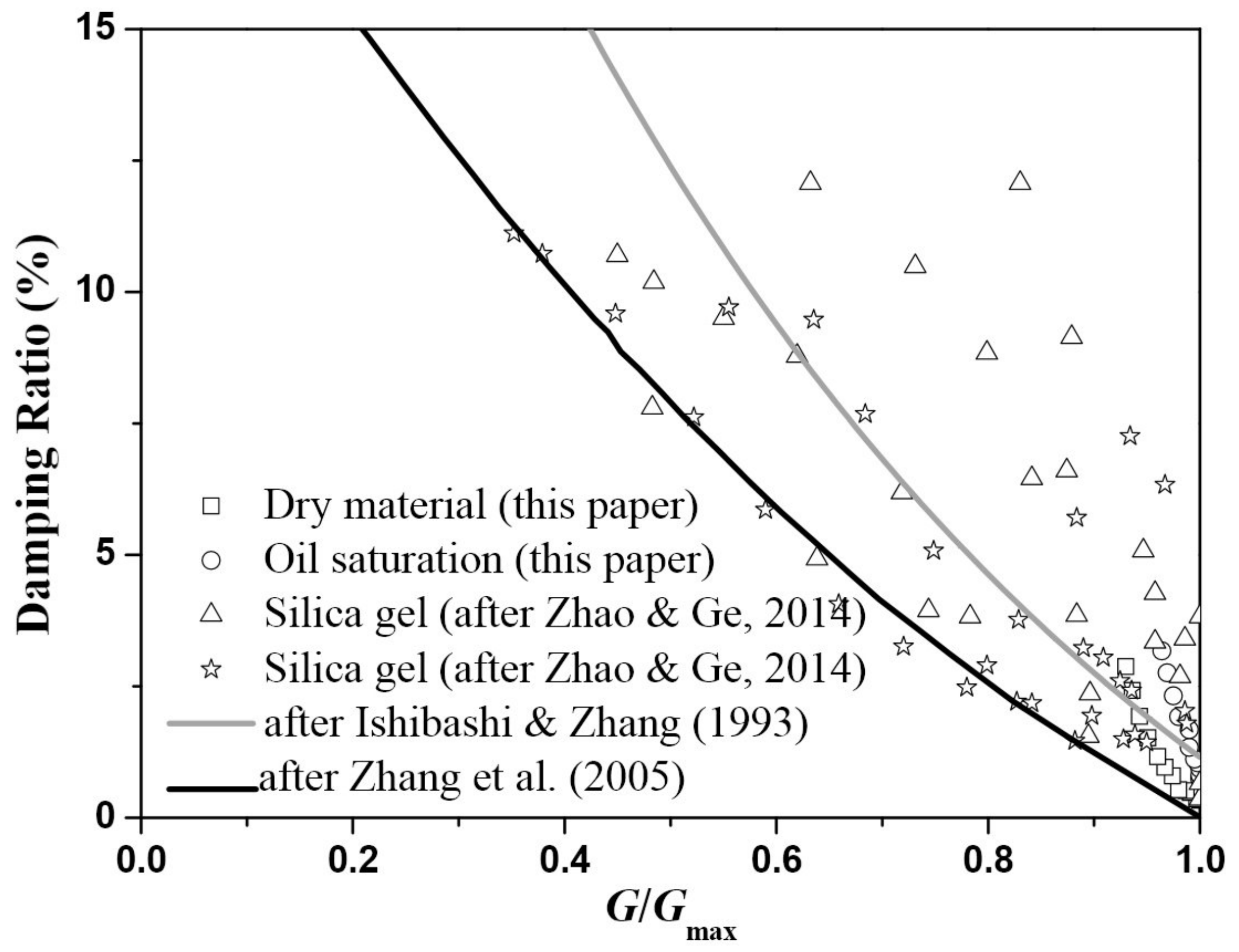

